\title{
Artistic Scanning as a Classroom Qualitative Research Activity \\ Steve Elliott
}

\author{
Degas was a master of composition in that he gave \\ you the impression that this (teacher points to an ant \\ reproduction) was just a little snippet of a much larger picture. \\ What's happening in this picture that gives you the idea that \\ there's much more going on? \\ Mark? \\ What was the question Mark? \\ I don't know \\ Am I putting you to sleep? Listen to the question carefully. \\ There's something about this composition, and about Degas' \\ compositions generally, that make you think that there's more \\ going on than just what you see. What might that be? \\ Becky? \\ (Elliott, 1997)
}

How does the teacher decide what questions to ask to make viewing art sessions as meaningful as possible for her students? Are the questions and the approach the same for all types of art? What happened to Mark? Did he know the answer?

The thesis for this paper grew out of my current research into the nature of teacher directed dialogue during art viewing sessions in secondary schools. During the data collecting sessions it appeared that some, and at times many, of the students in the various classes being studied were only superticially involved in the investigation of works of art. In addition to their apparent disengagement with the process, student comprehension often seemed to be a product of rote memory rather than deep personal understanding.

As an outside observer I became interested in considering the method and content of such interactions with respect to what facility the process and content of these sessions offered the students in making sense of the objects being discussed. I began my observations by attending to how the students made sense of each work viewed as an example of a particular style or type of artistic expression and then to how the individual works related to a larger group of things we call art. With an interest in making the art viewing activities within classrooms as productive and meaningful for the students as possible, this work suggests that by conceiving of and constructing the art viewing session as a qualitative research activity student involvement and understanding may be enhanced.

Talk About Art, Scanning and Frameworks

It is within the frame of critical and descriptive dialogue that students explore understandings and value regarding historical works, student creations

Marilyn Zurmuehlen's Working Papers In Art Education 1996-1997 
and aesthetic categories of art (Feldman, 1994). In fact, "art criticism has become the storytelling aspect of art and aesthetics and transforms visual experiences into verbal expressions that can be shared with others." (Cromer, 1990, p.9)

Meaning and value in art then, are not taught solely through beholding. They are explored and understood through language associated with what we see. To facilitate instruction, teachers often employ a framework or regularized viewing process to organize student interaction with works of art.

Viewing art frameworks provide structures that direct the what's and the how-to's of looking at art. Their purpose is to make the viewing process as transparent and worthwhile as possible for both teachers and students. What is talked about during criticism sessions has the effect of drawing attention to characteristics or qualities of a given work that are of value to the work as it is revealed as an art object. Through these sessions the teacher "advances ideas that guide the viewers in their interactions with art" (Feldman, 1994, pg. 4).

A viewing art framework is intended to provide a set of categories that allow artistic experience to be parsed up and analyzed in specific terms related to strategies used by artists to shape the expression found in their work. The use of guiding categories narrows the range of expressive possibilities to be attended to and thereby limits discussion to those specific qualities identified by the framework as being most relevant to understanding art. An explicit outline can make instruction easier, and understanding clearer, and more focused for both students and teachers.

In addition to the possible explication virtues of using a specific set of terms during art viewing sessions, many schools, limited by reduced teacher expertise or shrinking time allocation for Visual Art instruction, can benefit from the use of frameworks as an organizational tool to guide classroom activity. The structure and process of working effectively with a framework can usually be taught to, and mastered by, students and teachers in a relatively short period of time (Broudy, 1987)

With a framework in place teachers may work together with their students in scanning the works to be studied. Scanning is the process of carefully observing and describing the specific expressive nature of a given work of art while using an outline of possible expressive qualities as a guide. According to Broudy (1987), scanning is a worthwhile strategy for viewing art because by using the framework as a guide it teaches a specific kind of insightful, artistic perception which is distinct from ordinary or general perception.

\section{Existing Frameworks}

Notwithstanding the instructional process advantages that scar ing can offer art educators, strategies like Broudy's aesthetic scanning framework (Broudy, 1972) which advocates a single perspective for viewing art run the risk of having students look at art through incompatible or non illuminating perspectives It would be ineffective, by way of example, to analyze an Egyptian artifact through 
a modernist viewing paradigm. Each stylistic movement in art has its own particular way of viewing its creations.

The main problem of working with a great number of varied perspectives, like the expressive variety that exists in the collective canon of art, is to conceive of some organizing principle that will assist those involved in analyzing art in making both individual and collective sense of the works being considered. Such a principle must be individuatly illuminating, so as to retain the integrity of each work of art in the context of its creation, as well as be able to provide a place for the individual items within a broader range of things called art. As a result, items of interest are individually understood while, at the same time, collectively related.

Historically the notion of art as expression has been a useful principle around which to structure classroom discussion (Arnheim, 1971, Broudy, 1972). The term expression means that all art is intended to produce in the viewer a feeling that creates interest in the work as a physical entity, or in ideas or concepts for which the physical entity acts as a catalyst or point of entry into issues of interest. Simply stated. the general purpose for activity in visual art is expression. The art object represents, documents, embodies, or is a catalyst for an expressive experience. Art as expression has also been explored in other cultures as the way in which an artifact is deemed special or set apart from other experiences (Dissanayake, 1988).

One difficulty with existing frameworks (Broudy, 1987, 1972, Feldman, 1994 ) is that they were developed for use in analyzing works of modern art or works of other styles of art from a modem perspective. Modern art standards for shaping artistic expression are being eroded or rather exploded by a plethora of postmodern ideas. The use of sensory qualities, like colour and tone, or formal qualities, like emphasis and balance to carry the main expressive impact of works of art has been replaced in contemporary works by socially constructed conceptual triggers of expression. Many postmodern artists have rejected formal properties as their primary concern (Parks, 1988) and for some, aesthetic issues play no role in the expression of their work (Tilgman, 1984). As viewers of modern art are expected to experience a felt response because of what they perceive visually as being in the work itself, viewers of postmodern creations are asked to feel about the work because of what they think about what they see. Formalism is giving way to narration, metaphor, allegory, juxtaposition etc. (Parks, 1989).

In addition to the changing notions of art in a postmodern world there is the increased need to incorporate the arts of other cultures into classroom investigations (Koroscik, 1996). As euro-western artistic expression has moved beyond its modernist boundaries and the ethnic composition of our nations classrooms has become increasingly diverse, what constitutes clarity. understanding and contextual integrity, when talking about works of art in school has broadened.

Although some may call for an overhaul of traditional art education practices from a modemist to a postmodernist approach (see Wolcoth, 1996 Fehr, 1994, Parks, 1989), the fact that the world of art has changed and 
broadened does not necessarily mean that we must abandon familiar practices for viewing art. An instructional paradigm that simply replaces the protocols of working with modern art by ones that provide a postmodern perspective will run the risk of exchanging one narrow paradigm with a different, yet potentially equally narrow view. Not only has our world become postmodern, it has also become international and multicultural. As a result it may be prudent, from an art education perspective, to adopt practices that accommodate postmodernist paradigms as well as international and multicultural perspectives. If art education is to have integrity as a contemporary educational pursuit it must become increasingly inclusive and comprehensive in its scope not simply transposed to postmodern practice. As a result, any general frameworks to guide the viewing art process must use categories that can accommodate a wide variety of art styles types and contexts.

\section{Engaging Students by Building a Framework as a Research Activity}

Two initial concerns stated in this paper suggested that students are sometimes disengaged in the process of art investigation and that learning gleaned from these sessions often seemed a product of rote memorization rather than a synthesized personal position.

The suggestion being made here is that both of these instructional difficulties may be reduced or overcome if teachers adopt a research approach to viewing art in their classrooms. Through research both students and teachers become involved in the process of not only managing information that reflects value in works of art, but also involves them in structuring the frameworks that will help them make sense of what they are looking at and evaluating.

As students and teachers explore together the ways in which artists construct visual value through expression they are engaging in action research The learning that grows out of these types of activities will be more meaningful for both teachers and students than if the same information is read from a research report or textbook (Reynolds, 1983). As co-researchers they develop the tools that allow them to recognize and understand relevant information. In short, researchers are more involved with, and have an opportunity to better understand, the data than those who simply read about the research .

As mentioned earlier, in viewing art activities teachers and students are required to analyze objects that communicate or express as an important part of their function as art. Researchers working with communication materials have traditionally used a methodology known as content analysis which is described as a process for the systematic study of communication material (Berelson, 1971). Generally content analysis is viewed as a quantitative research activity but has great potential as a qualitative research paradigm as well. When conceived as a qualitative approach it allows for greater richness in description of data (Berelson, 1971). Although content analysis is typically used to study and analyze text, it can offer the art teacher a powertul method for studying and analyzing the expression

Marilyn Zurmuehien's Working Papers In Art Education 1996-1997 
of visual art. Berelson (1971) suggests that communication content can include meanings derived through verbal, musical, pictorial, plastic or gestural symbols.

Since content analysis consists of making sense of communication materials, teachers can be seen to use informal content analysis as a regular part of their professional practice while correcting papers and guiding classroom discussions. As teachers include students in this process in a formal way they are engaging in research as an instructional approach (Reynolds, 1983).

To more fully involve the students in the process and to deepen their understanding, teachers and students can use basic content analysis protocols to identify and construct categories to be used in the shaping of a framework for scanning. By constructing the framework as co-operative activity, the students may more easily see it as a negotiable structure used to facilitate discussion rather than a fixed screen through which all art must pass.

For the purposes of this activity, content analysis methodology can be easily divided into seven specific steps (adapted from Johnson \& LaMontagne. 1993).

1. Identify of the basic problem or research question. In the case of viewing art research students and teachers are investigating how artifacts act as art. This question requires that an inclusive definition of art be agreed upon by the class which identifies general characteristics of objects that qualify them for consideration as art. It is important at this stage not to become too specific as to limit the definition to a particular iteration or style of art. Earlier it was suggested that art as expression may be a good starting point for this type of definition. In some ways this definition would describe the experience of art and the research process would become an experiential learning activity. For any activity to be considered an effective experiential learning enterprise it must first be connected to a significant purpose or unifying principle (Kolb, 1984). This purpose or principle becomes the guide for the activity. With a well understood purpose one may know in which direction to strive, or when the striving has been successful, or what types of activities including sensibilities could be considered significant in the experience. This principle may also provide an interpretative structure for making sense of feedback.

2. Prepare the data for analysis. The data is represented by works of art. Students and teachers will collect a sample of as many different types and styles of art as they will study. Each work of art will become a different item for analysis.

3. Become familiar with the data. View all collected works of ant and become familiar with their overall nature. Begin to recognize the particular way each work communicates with you as well as other possible audiences. During this phase both looking at and reading about the works of art and their cultural contexts may be required to understand the strategies that were used by the various artists to communicate and express. 
4. Identify units of analysis. Specifically identify the various means used to create interest and convey meaning in the works of art.

5. Define tentative categories. Identify general categories that describe the expression (communication) strategies used in each work and into which they will be divided.

6. Refine categories. Combine categories that seem to relate to similar expressive strategies and generalize categories that can accommodate more than one of the specific strategies identified. For example, if the students find that in one work colour is used as an expressive element and in another texture is used, both could be considered sensory characteristics of expression and communication. If violence against women is the expressive theme in one work and destroying the environment is the theme of another, social issues could be used as a general category to accommodate both. This refining process is ongoing throughout the research.

7. Create a framework. The categories identified are then organized into a list to be used as a guide as works of art are scanned during classroom discussion. This comprehensive list will facilitate general understanding about the nature of art as well as assist students in making comparative assessments between styles and cultures of art. As new cases are encountered by the students that are not accommodated by their category list, new ones can be added or old ones modified making this type of framework a dynamic guide.

\section{Concluding Thoughts}

Content analysis is an excellent example of action research (Reynolds, 1983) that lends itself to the study of abstract concepts, emotions, and thought processes that are difficult to study through other forms of applied behavioral research (Johnson \& LaMontagne, 1993). Through this approach to viewing art, students and teachers may benefit from the activity because as co-researchers that shape the research instrument, each will have the possibility of greater understanding. Understanding the relevance of classroom discussion could make the school experience more worthwhile for students and understanding the tools and methods of analysis could facilitate further independent study

\section{References}

Arnheim, R. (1971). Art and visual perception. Berkeley, CA: University of California Press.

Berelson. B. (1971). Content analysis in communication research. Glencoe, IL: Free Press.

Broudy, H S. (1972). Enlightened cherishing: An essay on aesthetic education. Kappa Delta Phi Lecture 
Broudy, $\mathrm{H}$. (1987). The role of imagery in learning. Los Angeles: The Getty Center for Education in the Arts. Los Angeles, California.

Cromer, J. (1990). Criticism, history, theory and practice of art criticism in art education. The National Art Education Association, Reston, Virginia.

Dissanayake, E. (1988). What is art for? Seattle, WA: University of Washington Press.

Elliott, S. (1997). [ Classroom dialogue during art viewing session in a secondary school]. Unpublished raw data.

Fehr, D. (1994). Promise and paradox: ant education in the postmodern arena. Studies in Art Education, 34 (4),p. 209-217.

Feldman, E. (1994). Practical art criticism. Englewood Clifts, New Jersey. Prentice Hall.

Johnson, L. \& LaMontagne, M. (1993). Research methods. Journal of Early Intervention. 17(1), 73-79.

Kolb, D. A. (1984). Experiential learning. Englewood Cliffs, New Jersey. Prentice-Hall

Koroscik, J. (1996). Understanding art in the information age. Studies in Art Education, 38 (1),p. 4-20.

Parks, M. (1988). How does the work mean? Art Education, 41, 55-61.

Parks, M. (1989). Art education in a postmodern age. Art Education, 42 (2), $10-13$

Reynolds, J. (1983). Content analysis in the classroom. Reading Improvement, 20(2), 111.113

Tilghman, B. (1984). But is it art ? Oxford, UK: Basil Blackwell.

Wolcott, A. (1996). Is what you see what you get? a postmodern approach to understanding works of art. Studies in Art Education, 37 (2),p. 69-79. 